\title{
A RASCH-BASED COMPARISON OF THE FUNCTIONAL INDEPENDENCE MEASURE AND SPINAL CORD INDEPENDENCE MEASURE FOR OUTCOME AND OUALITY IN THE REHABILITATION OF PERSONS WITH SPINAL CORD INJURY
}

Roxanne MARITZ, PhD ${ }^{1,2 *}$, Carolina FELLINGHAUER, PhD ${ }^{1 *}$, Mirjam BRACH, MBA, MPH ${ }^{1}$, Armin CURT, MD ${ }^{3}$, Hans Peter $^{2}$ GMÜNDER, MD ${ }^{4}$, Maren HOPFE, PhD ${ }^{1}$, Margret HUND-GEORGIADIS, MD, PhD ${ }^{5}$, Xavier JORDAN, MD ${ }^{6}$, Anke SCHEELSAILER, MD ${ }^{2,4}$ and Gerold STUCKI MD, MS ${ }^{1,2}$

From the ${ }^{1}$ Swiss Paraplegic Research, Nottwil, ${ }^{2}$ Center for Rehabilitation in Global Health Systems, Department of Health Sciences and Medicine, University of Lucerne, Lucerne, ${ }^{3}$ Spinal Cord Injury Center, Balgrist University Hospital, Zurich, ${ }^{4}$ Swiss Paraplegic Centre, Nottwil, ${ }^{5}$ Clinic for Neurorehabilitation and Spinal Cord Injury, REHAB Basel, Basel and ${ }^{6}$ Clinique Romande de Réadaptation, Sion, Switzerland "Shared first authorship.

Objective: The Functional Independence Measure $\left(\right.$ FIM $^{\mathrm{TM}}$ ) and spinal cord injury (SCI)-specific Spinal Cord Independence Measure (SCIM) are commonly used tools for outcome measurement and quality reporting in rehabilitation. The objective of this study was to investigate the psychometric properties of FIM $^{\mathrm{TM}}$ and SCIM and to equate the 2 scales.

Methods: First, content equivalence of FIM $^{\mathrm{TM}}$ and SCIM was established through qualitative linking with the International Classification for Functioning, Disability and Health (ICF). Secondly, a Rasch analysis of overlapping contents determined the metric properties of the scales and provided the empirical basis for scale equating. Furthermore, a transformation table for FIM $^{\mathrm{TM}}$ and SCIM was created and evaluated.

Subjects: Patients with SCI in Swiss inpatient rehabilitation in 2017-18.

Results: The ICF linking and a separate Rasch analysis of FIM $^{\mathrm{TM}}$ restricted the analysis to the motor scales of FIM ${ }^{\mathrm{TM}}$ and SCIM. The Rasch analysis of these scales showed good metric properties. The co-calibration of FIM $^{\mathrm{TM}}$ and SCIM motor scores was supported with good fit to the Rasch model. The operational range of SCIM is larger than for FIM ${ }^{\mathrm{TM}}$ motor scale. Discussion: This study supports the advantage of using SCIM compared with FIM ${ }^{\mathrm{TM}}$ for assessing the functional independence of patients with SCI in rehabilitation.

Key words: spinal cord injury; Functional Independence Measure; Spinal Cord Independence Measure; activities of daily living; Rasch measurement model; psychometrics; outcome assessment (healthcare); quality in healthcare; rehabilitation.

J Rehabil Med 2022; 54: jrm00262

Accepted Dec 16, 2021; Epub ahead of print Jan 25, 2022

Correspondence address: Roxanne Maritz, Department of Health Sciences and Medicine, University Lucerne, Frohburgstrasse 3, 6002 Lucerne, Switzerland. E-mail: roxanne.maritz@unilu.ch

$\mathrm{O}$ ver the last decade, health systems have established national quality monitoring systems to strengthen quality assurance and quality management by providing a strategy for performance comparison across healthcare providers (1). To measure and ensure

\section{LAY ABSTRACT}

In our study we compared two rehabilitation outcome assessment tools commonly used to measure functional independence in Spinal Cord Injury: the Functional Independence Measure (FIM ${ }^{\mathrm{TM}}$ ), a general tool, and the Spinal Cord Independence Measure (SCIM), a tool specifically developed for Spinal Cord Injury rehabilitation. We first compared the content of the two tools using the International Classification of Functioning Disability and Health (ICF). Then we tested their measurement properties and put them on a common measurement scale, which allows to directly compare scores of the two tools. The common measurement scale was obtained by mean of a so-called Rasch analysis. The results showed that the FIM $^{\mathrm{TM}}$ motor items can be compared to the SCIM items from a content but also from a metric point of view. The study showed an advantage in using the SCIM compared to the FIM ${ }^{\mathrm{TM}}$ for assessing the functional independence of patients in Spinal Cord Injury rehabilitation.

an adequate depiction of quality, these systems need to rely on important determinants to describe case complexity, such as diagnosis, treatment, and functioning information (2).

In the context of rehabilitation, the Functional Independence Measure (FIM ${ }^{\mathrm{TM}}$ ) has been established in several countries as a standard for measuring change at patient level and outcome quality at institutional or national level (e.g. in Australia or Canada) (3-6).

In Switzerland, the National Association for Quality Development (ANQ) (7), an organization mandated by the Swiss cantons, health insurances, and clinics, has also established a quality monitoring system including FIM $^{\mathrm{TM}}$ for musculoskeletal and neurological rehabilitation.

Quality monitoring of rehabilitation services for rehabilitation outcomes has its merits, including the possibility to learn from best practices. Nevertheless, the imposition of an instrument such as the FIM ${ }^{\mathrm{TM}}$ as a standard patient assessment instrument can pose challenges for the adequate depiction of case complexity of relevant subgroups and subsequent reporting of outcome quality. 
Patients with spinal cord injury (SCI) differ from those with neurological and musculoskeletal disorders in terms of their rehabilitation needs (8). They exhibit higher medical complexity, which requires treatment in specialized rehabilitation centres with the corresponding infrastructure, personnel, and processes (9). In order to consider the medical and rehabilitative characteristics of this group of patients, specific survey instruments are required to ensure a complete and meaningful illustration of the patients' functioning.

For rehabilitation patients with SCI, the FIM ${ }^{\mathrm{TM}}$ was found to be unsatisfactory for assessment and followup of functional independence $(10,11)$. Consequently, a SCI-specific assessment instrument, the Spinal Cord Independence Measure (SCIM) was developed (12). Compared with the FIM ${ }^{\mathrm{TM}}$, the SCIM does not include cognitive items, but instead it addresses several issues typical for SCI, such as respiration problems, bladder and bowel management, and transfer and walking ability, including usage of SCI-related mobility aids.

In Switzerland, the specialized rehabilitation clinics for SCI have conducted a project to examine whether it would be possible to calculate functioning scores equally to FIM ${ }^{\mathrm{TM}}$ scores based on SCIM. As the SCIM can be expected to suit the SCI population better than the FIM ${ }^{\mathrm{TM}}$, using the SCIM in SCI rehabilitation would enable collecting more clinically meaningful data on the one hand, and, through an equating of the 2 metrics, provide data comparable to the FIM ${ }^{\mathrm{TM}}$ for the national quality management on the other hand. The Swiss SCI centres also hypothesized that the daily independence of patients with a lower level of functioning would be better assessed with the SCIM than with the FIM ${ }^{\mathrm{TM}}$ and, consequently, reduce bias against clinics with highly dependent patients for which the FIM ${ }^{\mathrm{TM}}$ can be expected to show a floor effect.

The objective of this study was to investigate the psychometric properties of FIM ${ }^{\mathrm{TM}}$ and SCIM and to equate the 2 scales for outcome measurement and quality management in SCI. This would help to examine whether SCIM can replace FIM ${ }^{\mathrm{TM}}$ for outcome measurement and quality management purposes.

\section{METHODS}

\section{Design}

Rasch-based score equating based on a common person design.

\section{Sample}

From May 2017 to March 2018, all specialized SCI clinics in Switzerland collected FIM ${ }^{\mathrm{TM}}$ and SCIM III data in parallel for the same patients with SCI. The data collection was part of a larger investigation for the development of a new reimbursement system in rehabilitation, which aims to include the same assessment tools already used for national quality reporting (13). A total of 663 patients with SCI were assessed 1-6 times for 6 weeks, resulting in a total of 985 observations. Approximately $66 \%$ of the patients participated in 1 wave of data collection, $22.3 \%$ in 2 waves, $8.5 \%$ in 3 waves, and $2.5 \%$ in 4 waves of data collection. Only 2 participants underwent 5 and 6 measurements, respectively. To avoid repeated person measures in the sample, only data from 1 assessment time-point was randomly selected from each individual (14).

\section{Assessment tools}

The FIMTM was developed in the 1980s (3) and is currently one of the most commonly used functioning assessment instruments in neurological and musculoskeletal rehabilitation (10). The instrument consists of 18 items, with 13 items on motor and 5 items on cognitive abilities. The motor domain is further divided into 4 subscales: "self-care", "continence", "transfer", and "locomotion" (mobility). The cognitive domain consists of 2 subscales: "communication" and "cognition". For each item, 7 response options, from "total assistance" to "complete independence" evaluate the degree of dependence in everyday autonomy.

The psychometric properties of FIM ${ }^{\mathrm{TM}}$ have been extensively studied (15). Studies comparing FIM ${ }^{\mathrm{TM}}$ with similar instruments designed to address functional independence in SCI, showed that, despite FIM ${ }^{\mathrm{TM}}$ sharing many similarities with these instruments, they often do not cover all areas equally well (10, 16-20).

The SCIM was developed in the mid-1990s as the first outcome measure for everyday independence in SCI. Since then, the SCIM has been widely used in SCI rehabilitation (12). The current version of the SCIM is SCIM III (21). The SCIM comprises a total of 18 items, divided into 4 subscales: "self-care", "respiration and sphincter management", "mobility in rooms", and "mobility indoors and outdoors" (mobility). The response scales vary between $0-2$ and $0-15$ points. The total score, which covers only motor functioning, ranges from 0 "total assistance" to 100 "complete independence".

SCIM and FIM ${ }^{\mathrm{TM}}$ are both reliable and valid assessment tools for measuring everyday independence (10). Studies support the good correlation of the FIM ${ }^{\mathrm{TM}}$ with the SCIM III. Still, there is also some evidence that the SCIM III has a higher sensitivity and responsiveness for patients with SCI $(22,23)$.

\section{Data analysis}

Qualitative linking: ICF-based content comparison. Scale equating refers to methods establishing equivalence of total scores from different assessment tools so that the scores are interchangeable (24). Qualitative linking was applied to determine the conceptual overlap and similarities, of FIM ${ }^{\mathrm{TM}}$ and SCIM. Equality of constructs is an essential requirement for scale equating (24). The International Classification of Functioning, Disability and Health (ICF) (25) is a WHO classification that provides a standardized and international language to describe health and functioning. The ICF was used for qualitative linking, as both FIM ${ }^{\mathrm{TM}}$ and SCIM assess functioning information. Concepts identified in both assessment tools were linked by 2 researchers to the most precise ICF category, using the current version of the standardized ICF linking rules (26).

Furthermore, selections of relevant ICF categories for different settings and health conditions, so-called ICF Core Sets, can be consulted to discuss the relevance of assessed functioning information. In a second step, the content of the FIM ${ }^{\mathrm{TM}}$ and the SCIM identified through the ICF linking was contrasted with the content of the ICF Generic-30 Set, representing relevant 
functioning categories for neurological, musculoskeletal, and cardiovascular rehabilitation (27).

Quantitative equating: metric equivalence. Metric properties of total scores of assessment instruments, such as SCIM and FIM $^{\mathrm{TM}}$, can be evaluated with a modern probabilistic measurement approach. Rasch analysis, applying the partial credit model (PCM), was used in the current study. The PCM is a model developed for the psychometric analysis of ordinal response scales (28). Previous studies have shown that PCM is suitable to calibrate the FIM ${ }^{\mathrm{TM}}(15)$.

A Rasch analysis examines critical assumptions for reliable measurement with ordinal scales, such as the underlying dimensionality, the monotonicity of the response options, or the conditional independence of items when having conditioned out the total score (29). If the outcome of a Rasch analysis fulfils the model's assumptions, it can be concluded that the total scores are interval scaled and applicable for quantifying change and making comparisons (30).

It has been shown that FIMTM (15), as well as SCIM III (31), are multidimensional assessment instruments, exhibiting local dependencies within subscales. Thus, the redundant information within domains often enters the analysis as testlets, i.e. as a sum score aggregating the respective subscale items. For this study, 3 testlets were formed for the motor items of the FIM ${ }^{\mathrm{TM}}$ and SCIM: "self-care", "continence", and "mobility". Furthermore, 1 testlet was formed with all the cognitive items of the FIM" incorporating the two areas: "communication" and "cognition".

Some response options of SCIM III items are coded in a non-uniform and non-equidistant manner, such as the SCIM's breathing item with 6 non-uniform options (0-2-4-6-8-10) or the SCIM's bowel management item with 4 non-equidistant options (0-5-8-10). For the metric analysis presented in this study, the non-uniform non-equidistant response options of the SCIM have been recoded to represent incremented values starting from 0 with directly consecutive integers. Without this modification, the Rasch model would estimate more thresholds than available by considering the response gaps as missing information. As the PCM does allow thresholds to be non-equidistant, the increase in difficulty of response thresholds will be estimated by the model directly.

Only if the qualitative linking confirms the construct equality and the metric properties of the scales show fit to the Rasch model, can scale equating be conducted.

In the current analysis, FIM ${ }^{\mathrm{TM}}$ and SCIM data were collected for all participants (common person design). In a common person equating procedure, given that the scales to equate fit the Rasch model, a co-calibration of the row scores of the scales can be undertaken. The fit of the respective scales to the Rasch model is given by the total-Item $\chi^{2}$ test. When co-calibrating two scales or subscales by their total scores, the quality of the model fit, i.e. a good adaptation of the data to the model, is given with a conditional $\chi^{2}$ fit statistic (32).

In a Rasch analysis, the reliability of the model can be measured with the Cronbach $\alpha$ and the Person Separation Index (PSI). A PSI $>0.85$ indicates high reliability for measurements at individual levels. A PSI $>0.8$ still indicates good reliability of the instrument for measurements at the population level (29). Cronbach $\alpha$ is interpreted similarly. A scale equating, based on total scores of two scales, is comparable, technically speaking, to an analysis with testlets, but represents a bi-factor equivalent solution. In a Rasch analysis that uses testlets instead of items, the change in reliability, given by the PSI or the Cronbach $\alpha$, can be described by mean of the A-score. The A-score is understood as the percentage of the remaining variance observed after ag- gregation of the items. A-scores above $90 \%$ indicate that more than $90 \%$ of the unique variance of the items is retained by a testlet formation. The interpretation of the A-score is similar to the Explained Common Variance used in bi-factor analysis, where values of $80 \%$ would indicate a strong first factor (33). According to Quinn (34), A-values above $90 \%$ are a minimum threshold and $\mathrm{A}$-values $<70 \%$ indicate that a multidimensional model is needed.

A dimensionality analysis was used to evaluate whether testlets measure the same latent construct. Ability estimates derived from oppositely loading testlets on the first principal component are compared individually with a $t$-test for each participant, and the number of significant deviations is determined. In the presence of unidimensionality, the proportion of significant $t$-tests should not exceed $5 \%$, meaning that the lower boundary of the $95 \%$ confidence interval $(95 \% \mathrm{CI})$ should not be above $5 \%(35)$

If the metric properties of FIM ${ }^{\mathrm{TM}}$ and SCIM allowed for it, a co-calibration of the scales would deliver a transformation table, indicating how a total score from one assessment tool can be translated into the total score of the other tool. Information from the entire population $(n=985)$ was used to analyse the quality of a SCIM to FIM ${ }^{\mathrm{TM}}$ motor total score transformations. The equivalence of the transformed FIM ${ }^{\mathrm{TM}}$ motor scores, as derived from SCIM with the observed FIM ${ }^{\mathrm{TM}}$ motor scores, was compared with the Spearman's rank correlation, the Wilcoxon signed-rank test (36), and Cohen's D effect size (37). The validity of the transformation table was then determined by comparing the FIM $^{\mathrm{TM}}$ motor scores resulting from the transformation table, as derived from SCIM with the truly observed FIM ${ }^{\mathrm{TM}}$ motor scores, as assessed with the scale. Likewise, the accuracy, in terms of correctly predicted FIM ${ }^{\mathrm{TM}}$ scores, can be described.

In addition, the Leunbach's model for direct equating has been applied (38), to test whether the two scales measure the same latent construct by relating the respective total scores to a common metric. This analysis provides, among other key values, a Cohen's kappa and a mean weighted standard error of equating (SEQ) (39). A Cohen's kappa of zero indicates that the agreement is equivalent to chance. Values of 0.4-0.6 represent moderate agreement, 0.6-0.8 substantial agreement, 0.8-0.99 near-perfect agreement, and 1 perfect agreement. An SEQ mean below 0.91 is acceptable (40).

Due to a very small percentage of missing values in a few cognitive items of the FIM ${ }^{\mathrm{TM}}$ and the ability of the Rasch model to handle missing values, no data were imputed. The Rasch analyses were performed with the software RUMM2030 (34). Leunbach's model analyses for scale equating were conducted with DIGRAM (41), and all further quantitative analyses with R (42).

\section{RESULTS}

Descriptive statistics of FIM ${ }^{\mathrm{TM}}$ and SCIM scores, including frequencies and proportions for the complete dataset and the analysis sample, are shown in Appendices 1 and 2. Further sample characteristics, such as age, sex, lesion level, etc., were not provided in the dataset for the current study.

\section{Qualitative linking: ICF-based content comparison}

The ICF linking of SCIM and FIM ${ }^{\mathrm{TM}}$ (Table I) showed that the items of both assessment tools contain ICF 
Table I. International Classification for Functioning, Disability and Health (ICF) linking

\begin{tabular}{|c|c|c|c|c|c|c|}
\hline ICF-Code & Titel & Bereich & FIM $^{\text {TM }}$ & FIM $^{\text {TM }}$ Item No. & SCIM & SCIM Item No. \\
\hline b144 & Memory functions & Cognitive & $x$ & FIM R & & \\
\hline b440 & Respiration functions & Continence & & & $x$ & SCIM 7 \\
\hline b525 & Defecation functions & Continence & $x$ & FIM H & $x$ & SCIM 8 \\
\hline b620 & Urination functions & Continence & $x$ & FIM G & $x$ & SCIM 9 \\
\hline $\mathrm{d} 175$ & Solving problems & Cognitive & $x$ & FIM Q & & \\
\hline d310 & Communicating with - receiving - spoken messages & Cognitive & $x$ & FIM N & & \\
\hline d315 & Communicating with - receiving - nonverbal messages & Cognitive & $x$ & FIM N & & \\
\hline d320 & Communicating with - receiving - formal sign language messages & Cognitive & $x$ & FIM N & & \\
\hline d325 & Communicating with - receiving - written messages & Cognitive & $x$ & FIM N & & \\
\hline d330 & Speaking & Cognitive & $x$ & FIM O & & \\
\hline d335 & Producing nonverbal messages & Cognitive & $x$ & FIM O & & \\
\hline d340 & Producing messages in formal sign language & Cognitive & $x$ & FIM O & & \\
\hline d345 & Writing messages & Cognitive & $x$ & FIM O & & \\
\hline $\mathrm{d} 410$ & Changing basic body position & Mobility & & & $x$ & SCIM 11,12 \\
\hline $\mathrm{d} 420$ & Transferring oneself & Mobility & $x$ & FIM I, J, K & $x$ & SCIM $12,13,18,19$ \\
\hline $\mathrm{d} 450$ & Walking & Mobility & $x$ & FIM L, M & $x$ & SCIM $14,15,16,17$ \\
\hline $\mathrm{d} 465$ & Moving around using equipment & Mobility & $x$ & FIM L & $x$ & SCIM $14,15,16$ \\
\hline d520 & Caring for body parts & Self-care & $x$ & FIM B & $x$ & SCIM 6 \\
\hline d530 & Toileting & Self-care & $x$ & FIM F, G & $x$ & SCIM $8,9,10$ \\
\hline d540 & Dressing & Self-care & $x$ & FIM D, E & $x$ & $\operatorname{SCIM} 4,5$ \\
\hline d550 & Eating & Self-care & $x$ & FIM A & $x$ & SCIM 1 \\
\hline d560 & Drinking & Self-care & $x$ & FIM A & $x$ & SCIM 1 \\
\hline d710 & Basic interpersonal interactions & Cognitive & $x$ & FIM P & & \\
\hline
\end{tabular}

FIM $^{\mathrm{TM}}$ : Functional Independence Measure; SCIM: Spinal Cord Independence Measure.

categories of the chapters $\mathrm{d} 4-$ Mobility and $\mathrm{d} 5$ - Selfcare, b5 - Functions of the digestive, metabolic and endocrine systems, and b6-Functions of the urogenital and reproductive systems. Except for the categories b440 Respiration and d410 Changing basic body position, the same ICF categories are addressed through the motor items of FIMTM and SCIM. ICF categories from chapters b1 - Mental functions, d1 - Learning and application of knowledge, $\mathrm{d} 3$ - Communication and $\mathrm{d} 7$ - Interpersonal interactions and relationships occur only for the FIM ${ }^{\mathrm{TM}}$ and correspond to the cognitive items of the FIM ${ }^{\mathrm{TM}}$ (items N-R). The SCIM does not capture cognitive limitations. However, with the exception of 3 SCIM items (items1, 7 and 8), which are linked to b525 Defecation functions, b440 Respiration functions, and d560 Drinking, all other items can be mapped to the ICF Generic-30, in comparison with the FIM $^{\mathrm{TM}}$, where $5(\mathrm{H}, \mathrm{N}, \mathrm{O}, \mathrm{Q}$ and $\mathrm{R})$ of 18 items cannot be linked to the Generic-30, including mostly its cognitive items.

\section{Quantitative equation: metric equivalence}

The results of the Rasch analyses are shown in Table II. Rasch analysis of the FIM ${ }^{\mathrm{TM}}$ scale, including motor and cognitive domains, clearly supported its multidimensionality with $13.28 \%(11.5 \%-15 \%)$ significant $t$-tests. The multidimensionality is further confirmed with an A-score below 90\% (87.65\%). Together with the fact that SCIM does not assess cognitive domains, the decision was made to create a transformation metric that only includes the motor domains of FIM ${ }^{\mathrm{TM}}$.

The individual analyses of FIM ${ }^{\mathrm{TM}}$ motor and SCIM scale with a testlet-based approach, i.e. by aggregating the items by subscales of the motor domain, resulted in good model fit and targeting, without floor and ceiling

Table II. Sample size, number (\%) of floor and ceiling effects in the total scores, model adjustment, targeting with the mean item difficulty and the ability of persons, their standard errors and the dimensionality and reliability of individual and common Rasch analyses of Spinal Cord Independence Measure (SCIM) and Functional Independence Measure $\left(\mathrm{FIM}^{\mathrm{TM}}\right)(n=663)$

\begin{tabular}{|c|c|c|c|c|c|c|c|c|c|c|c|c|c|c|c|}
\hline & \multirow[b]{2}{*}{ Domain } & \multirow[b]{2}{*}{$\begin{array}{l}\text { Floor } \\
n(\%)\end{array}$} & \multirow[b]{2}{*}{$\begin{array}{l}\text { Ceiling } \\
n(\%)\end{array}$} & \multicolumn{3}{|l|}{ Modelfit } & \multirow[b]{2}{*}{$\begin{array}{l}\text { Item } \\
\text { difficulty } \\
M(S E)\end{array}$} & \multirow[b]{2}{*}{$\begin{array}{l}\text { Person } \\
\text { ability } \\
\text { M (SE) }\end{array}$} & \multicolumn{4}{|c|}{ Dimensionality } & \multicolumn{3}{|c|}{ Reliability } \\
\hline & & & & $\begin{array}{l}\text { Total- } \\
\text { Item } x^{2}\end{array}$ & DF & $p$-value & & & $\begin{array}{l}\mathrm{N} \text { sign. } \\
\text { T-tests** }\end{array}$ & $\begin{array}{l}\mathrm{N} \\
\text { without } \\
\text { extreme }\end{array}$ & $\begin{array}{l}\% \text { sign. } \\
\text { T-tests }\end{array}$ & $\begin{array}{l}\text { CI \% } \\
\text { sign. } \\
\text { T-tests }\end{array}$ & PSI & $\begin{array}{l}\text { Cron- } \\
\text { bach a }\end{array}$ & $\begin{array}{l}\text { A- } \\
\text { Score } \\
\%\end{array}$ \\
\hline \multicolumn{16}{|l|}{ Rasch analysis } \\
\hline FIM $^{\mathrm{TM} *}$ & $\begin{array}{l}\text { Motor \& } \\
\text { Cognitive }\end{array}$ & $1(0.15)$ & $2(0.3)$ & 272.52 & 36 & $<0.001$ & $0(0.31)$ & $0.04(0.37)$ & 77 & 580 & 13.28 & $11.5-15$ & 0.82 & 0.79 & 87.65 \\
\hline $\mathrm{FIM}^{\mathrm{TM} *}$ & Motor & $26(3.92)$ & $4(0.6)$ & 36.70 & 27 & 0.10 & $0(0.18)$ & $-0.18(0.66)$ & 12 & 663 & 1.81 & $0.2-3.5$ & 0.86 & 0.87 & 92.19 \\
\hline Co-calibration & & & & $a$ & & & & & & & & & & & \\
\hline SCIM-FIM ${ }^{\text {TM } *}$ & Motor & $6(0.9)$ & $1(0.15)$ & 113.67 & 136 & 0.92 & $0(0)$ & $-0.11(0.58)$ & 21 & 656 & 3.20 & $1.4-4.7$ & 0.92 & 0.93 & 98.82 \\
\hline
\end{tabular}

${ }^{a}$ Conditional test-of-fit $\mathrm{X}^{2}$. N: sample size; DF: Degrees of Freedom; M: mean; SE: standard error: Sign: significant; CI: confidence interval. 
Table III. Comparison of transformed and observed total scores with rank correlation, Wilcoxon signed-rank test, and Cohen's D measure of effect intensity

\begin{tabular}{lllllll}
\hline $\begin{array}{l}\text { Co- } \\
\text { calibration }\end{array}$ & $\begin{array}{l}\text { Rank } \\
\text { correlation }\end{array}$ & $\begin{array}{l}\text { Wilcoxon } \\
\text { rank test } \\
p \text {-value }\end{array}$ & $\begin{array}{l}\text { Expected } \\
\text { values } \\
\text { Mean (SD) }\end{array}$ & $\begin{array}{l}\text { Observed } \\
\text { scores } \\
\text { Mean (SD) }\end{array}$ & $\begin{array}{l}\text { Cohen's } \\
\text { D }\end{array}$ & Effect \\
\hline SCIM to FIM ${ }^{\text {TM M Motor }}$ & 0.917 & 0.534 & $33.84(23.59)$ & $32.88(22.94)$ & 0.041 & Negligible \\
\hline
\end{tabular}

FIM $^{\mathrm{TM}}$ : Functional Independence Measure; SCIM: Spinal Cord Independence Measure; SD: standard deviation.

effects (Table II). The assessment instruments' motor scales are one-dimensional and show good reliability (PSI $>0.85$ ). Based on these findings, an equating of the motor total scores was justified.

The equating of FIM ${ }^{\mathrm{TM}}$ motor and SCIM by mean of a co-calibration of their total scores, resulted in good model fit with good targeting and high reliability (PSI $>0.9$ ). Also, in the co-calibration context, the onedimensionality assumption was fulfilled. The A-value of the co-calibration was $98.82 \%$, indicating that less than $2 \%$ of the variance had to be discarded to achieve a unidimensional latent estimate. An equivalence of the constructs and the equivalence of the latent trait being assessed by FIM ${ }^{\mathrm{TM}}$ motor and SCIM scale were supported statistically.

A person-item map visualizing the distribution of the ability estimates and of the difficulty thersholds from the co-calibration of the SCIM and the FIMTM is shown in Appendix 3. The person-item map shows that the SCIM has additional difficulty thresholds for lower levels of functional independence.

The co-calibrations enabled total scores to be transformed from one scale to another. The transformed values can then be compared with the observed total score. The tables with the SCIM scores and the corresponding Rasch transformed FIM $^{\mathrm{TM}}$ motor scores are shown in Appendix 4. The score transformation is based on the sum of re-scored items, as specified in Appendices $2 \mathrm{a}-\mathrm{c}$. The derived and observed total scores correlated very highly $(\mathrm{r}>0.9)$. A direct comparison with the Wilcoxon signed-rank test showed no significant mean deviation between the total motor scores. Cohen's D values also supported that the observed deviations of the means are negligible (Table III).
Furthermore, the direct raw score equating under the Leunbach's model also supports that SCIM and FIM ${ }^{\mathrm{TM}}$ motor items measure a common latent construct. The Cohens' kappa statistic under Leunbach indicated substantial agreement among the raw scores $(\kappa=0.79)$. The mean weighted SEQ of 0.61 indicated that the scale equating results are acceptable.

The confusion matrix regarding the precision of the total score quantile transformation from SCIM to FIM $^{\mathrm{TM}}$ motor score showed the correctly equated total scores on the diagonal. The derivation of the FIM ${ }^{\mathrm{TM}}$ motor scores from the SCIM scores had a precision of $68.12 \%$ (Table IV). Notably, a substantial part of the unprecise transformations is adjacent to the diagonal in the next quantile, indicating that the observed departures from the correct transformation quantile are not excessive.

\section{DISCUSSION}

Qualitative linking with the ICF as a reference system enabled the content overlap between SCIM and FIM ${ }^{\mathrm{TM}}$ to be determined. Further separate quantitative testing of the FIM ${ }^{\mathrm{TM}}$ motor and SCIM scale with Rasch analysis revealed good metric properties and supported their co-calibration and creation of a transformation table. Co-calibration with Rasch showed that FIMTM motor scores could be derived from observed SCIM scores with sufficient reliability. The Leunbach's approach of direct test equating supported that the 2 scales measure a common latent construct. Statistical comparison of the observed and transformed FIM ${ }^{\mathrm{TM}}$ motor scores showed negligible differences. However, the precision of a transformation into FIM $^{\mathrm{TM}}$ quantile scores was $68.12 \%$, indicating that $68.12 \%$ of the FIM $^{\mathrm{TM}}$ scores transformed from the observed SCIM scores were correctly found in the observed FIM ${ }^{\mathrm{TM}}$ quantiles. The direction of the equating error, meaning systematic over- or under-estimation of the observed FIM $^{\mathrm{TM}}$ score when transforming from SCIM is not found in this analysis.

This study further showed that the

Table IV. Spinal Cord Independence Measure (SCIM) to Functional Independence Measure $\left(\mathrm{FIM}^{\mathrm{TM}}\right)$ motor score derivation vs FIM ${ }^{\mathrm{TM}}$ motor score quantile (Precision: $68.12 \%$; misclassification in the next quantile: $30.36 \%$ )

\begin{tabular}{|c|c|c|c|c|c|c|}
\hline & \multirow[b]{2}{*}{$\begin{array}{l}\text { Quantile } \\
\text { (Scores) }\end{array}$} & \multicolumn{5}{|c|}{ Expected FIM $^{\mathrm{TM}}$ Score } \\
\hline & & $\begin{array}{l}0 \% \\
(<13)\end{array}$ & $\begin{array}{l}25 \% \\
(13-27)\end{array}$ & $\begin{array}{l}50 \% \\
(28-53)\end{array}$ & $\begin{array}{l}75 \% \\
(54-77)\end{array}$ & $\begin{array}{l}100 \% \\
(>77)\end{array}$ \\
\hline \multirow{5}{*}{ 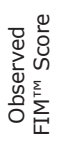 } & $0 \%(<12)$ & $10(1.02 \%)$ & $32(3.25 \%)$ & $0(0 \%)$ & $0(0 \%)$ & $0(0 \%)$ \\
\hline & $25 \%(13-27)$ & $2(0.2 \%)$ & $174(17.66 \%)$ & $41(4.16 \%)$ & $3(0.3 \%)$ & $3(0.3 \%)$ \\
\hline & $50 \%(28-53)$ & $0(0 \%)$ & $44(4.47 \%)$ & $134(13.6 \%)$ & $47(4.77 \%)$ & $5(0.51 \%)$ \\
\hline & $75 \%(54-77)$ & $0(0 \%)$ & $4(0.41 \%)$ & $57(5.79 \%)$ & $130(13.20 \%)$ & $58(5.89 \%)$ \\
\hline & $100 \%(<78)$ & $0(0 \%)$ & $0(0 \%)$ & $0(0 \%)$ & $18(1.83 \%)$ & $223(22.64 \%)$ \\
\hline
\end{tabular}

SCIM scores have a broader measurement range than the FIM $^{\mathrm{TM}}$ motor scores, being more able to determine limitations in functioning, especially in presence of low functional independence, regarding the mobility, self-care, and sphincter control independence experienced by more severely injured patients with SCI. 
This advantage can be explained by the differences of the content addressed by the SCIM subscales. For example, the continence subscale of the SCIM includes an item about respiration in addition to bowel and bladder management. "Respiration" is an item, which becomes particularly relevant with high levels of SCI where pulmonary functions are impaired due to the injury. Having more thresholds to differentiate lower levels of functioning means, concretely, that clinics treating a more severely affected patient population will be enabled to better report improvements achieved at the lower end of the continuum.

As all Swiss specialized SCI centres contributed to the collection of information on functional independence with SCIM and FIM ${ }^{\mathrm{TM}}$, the results are expected to be representative for the Swiss setting and can therefore be used to inform further developments of the Swiss ANQ quality reviews in SCI rehabilitation.

\section{Study limitations}

This study is based on secondary data analysis of a sample of persons with SCI. Information on sex, age, time since injury, lesion type and lesion level were not provided in the dataset. Therefore, a more refined analysis that could also determine the invariance of the scales across sample subgroups was not possible. Evidence from another Rasch analysis of the FIM ${ }^{\mathrm{TM}}$, with data from the Swiss national quality reports in a neurological and musculoskeletal population, supported the absence of differential item functioning for sex, age, nationality, insurance status of patients, rehabilitation group, clinic language, and time-point of measurement (4). More advanced research is needed in order to improve the precision of the score transformation. Availability of clinical cut-points for the scale score comparisons instead of using data driven cut-points (quantiles) may be of the highest benefit in that regard (43). Ultimately, the Rasch analyses of this report are based on a random sample of 663 participants with SCI.

\section{Applicability of results}

The study results support some advantages in using the SCIM III to assess independence in patients with SCI. When functional independence data is required for national quality reports or reimbursement purposes, SCIM scores could be transformed to FIM ${ }^{\mathrm{TM}}$ motor scores using a metrically sound transformation table. Furthermore, the Rasch analysis can be used to transform the ordinal-level scaled data to intervalscale level, which allows for sound comparisons and calculation of change scores in everyday independence.

Future research could focus on transformations at the subscale level, which could be more beneficial for monitoring in clinical practice. Furthermore, analysis of the invariance of the total scores for subgroups of the SCI sample, such as lesion level or age groups, may further improve the accuracy of the transformation. Considering injury and person characteristics would allow deriving group-specific reference values. These could be used in clinical practice to discuss the everyday independency of individuals in the light of normative scores.

\section{Conclusion}

This study allows us to equate and compare FIM ${ }^{\mathrm{TM}}$ motor and SCIM III scores. The results showed that SCIM III has a more comprehensive operational range, supporting the use of the SCIM III for SCI rehabilitation, as it provides more information for patients with lower functional abilities.

With respect to the motor domains, evaluations based uniquely on SCIM can be expected to result in a comparable benchmarking in comparison with other rehabilitation populations, in which the FIM ${ }^{\mathrm{TM}}$ has been used as outcome measure. In this regard, the assessment of patients with SCI based on SCIM instead of FIMTM may have a positive impact and result in more precise description of rehabilitation outcomes of SCI-specialized centres for quality reports.

\section{ACKNOWLEDGEIMENTS}

The authors thank Melissa Selb from the Swiss Paraplegic Research for support with ICF-related questions, Nuria Adroher for technical advice with DIGRAM, Stefan Metzger from the Swiss Paraplegic Clinic, and Renato Mattli from the Zürcher Hochschule für Angewandte Wissenschaften for their support in obtaining and understanding the dataset for secondary use.

\section{REFERENCES}

1. Busse R. Diagnosis-related groups in Europe moving towars transparency, efficiency and quality in hospitals. Maidenhead: Open University Press; 2011.

2. Prodinger B, Tennant A, Stucki G, Cieza A, Ustun TB. Harmonizing routinely collected health information for strengthening quality management in health systems: requirements and practice. J Health Serv Res Policy 2016; 21: 223-228.

3. Keith RA, Granger CV, Hamilton BB, Sherwin FS. The functional independence measure: a new tool for rehabilitation. Adv Clin Rehabil 1987; 1: 6-18.

4. Maritz R, Tennant A, Fellinghauer C, Stucki G, Prodinger $B$. The Functional Independence Measure 18-item version can be reported as a unidimensional interval-scaled metric: internal construct validity revisited. J Rehabil Med 2019; 51: 193-200.

5. Australasian Rehabilitation Outcomes Centre - University of Wollongong, Wollongong, Australia (2021 UOW). [Accessed January 10, 2022] Available from https: //ahsri. uow.edu.au/aroc/index.html.

6. Canadian Institute for Health Information: Better data. Better decisions. Healthier Canadians. Canadian Institute 
for Health Information, Ottawa, Canada (CIHI2022). [Retrieved January 10, 2022] Available from https://www. cihi.ca/en/about-cihi.

7. Swiss National Association for Quality Development in Hospitals and Clinics, Bern Switzerland (2022 ANQ). Review Information: Rehabilitation. [Accessed January 10, 2022] Available from https://www.anq.ch/en/departments/rehabilitation/review-information-rehabilitation/.

8. World Health Organization (WHO), ISCOS: International Perspectives on Spinal Cord Injury. Malta: World Health Organization; 2013.

9. Curt A, Hund-Georgiadis M, Jordan X, Baumberger M. Qualitäts- und Leistungskriterien für die Behandlung von Patienten mit einer Para- oder Tetraplegie sowie mit querschnittähnlicher Symptomatik. Nottwil: Swiss Society of Paraplegia; 2018.

10. Anderson K, Aito S, Atkins M, Biering-Sorensen F, Charlifue $S$, Curt $A$ et al. Functional recovery measures for spinal cord injury: an evidence-based review for clinical practice and research. Spinal Cord Med 2008; 31: 133-144.

11. Middleton JW, Harvey LA, Batty J, Cameron I, Quirk R, Winstanley J. Five additional mobility and locomotor items to improve responsiveness of the FIM in wheelchairdependent individuals with spinal cord injury. Spinal Cord 2006; 44: 495-504.

12. Catz A, Itzkovich M, Agranov E, Ring H, Tamir A. SCIM Spinal Cord Independence Measure: a new disability scale for patients with spinal cord lesions. Spinal Cord 1997; 35: 850-856.

13. Dettling M, Wirz M, Mattli R. ST Reha - Zusatzdatenerhebung: Parallelerhebung SCIM/FIM ${ }^{\circledR}$ in den Para-Kliniken im Jahr 2017/2018 : Finaler Schlussbericht. In. Zürcher Hochschule für Angewandte Wissenschaften: Winterthurer Institut für Gesundheitsökonomie; 2018.

14. Mallinson T. Rasch analysis of repeated measures. Rasch Meas Trans 2011; 25: 1317-1318.

15. Lundgren Nilsson A, Tennant A. Past and present issues in Rasch analysis: the functional independence measure (FIM) revisited. J Rehabil Med 2011; 43: 884-891.

16. Donnelly C, Eng JJ, Hall J, Alford L, Giachino R, Norton K, et al. Client-centred assessment and the identification of meaningful treatment goals for individuals with a spinal cord injury. Spinal Cord 2004; 42: 302-307.

17. Marino RJ, Shea JA, Stineman MG. The Capabilities of Upper Extremity instrument: reliability and validity of a measure of functional limitation in tetraplegia. Arch Phys Med Rehabil 1998; 79: 1512-1521.

18. Yavuz N, Tezyurek M, Akyuz M. A comparison of two functional tests in quadriplegia: the quadriplegia index of function and the functional independence measure. Spinal Cord 1998; 36: 832-837.

19. Marino RJ, Huang M, Knight P, Herbison GJ, Ditunno JF, Segal M. Assessing selfcare status in quadriplegia: comparison of the quadriplegia index of function (QIF) and the functional independence measure (FIM). Paraplegia 1993, 31: 225-233.

20. Morganti B, Scivoletto G, Ditunno P, Ditunno JF, Molinari $M$. Walking index for spinal cord injury (WISCI): criterion validation. Spinal Cord 2005; 43: 27-33.

21. Itzkovich M, Gelernter I, Biering-Sorensen F, Weeks C, Laramee MT, Craven BC et al. The Spinal Cord Independence Measure (SCIM) version III: reliability and validity in a multi-center international study. Disabil Rehabil 2007; 29: 1926-1933.

22. Stumm C, Hug K, Ballert C, Hund-Georgiadis M. Responsivität des »Spinal Cord Independence Measure« (SCIM) und des »Functional Independence Measure « (FIM) bei Personen mit Rückenmarksverletzung. Neurol Rehabil 2017; 23: 227-232.

23. Jones LAT, Li CY, Weitzenkamp D, Steeves J, Charlifue S, Whiteneck G. Development and validation of crosswalks
Between FIM(R) and SCIM III for voluntary musculoskeletal movement functions. Neurorehabil Neural Repair 2021; 35: 880-889.

24. Kolen MJ, Brennan RL, Kolen MJT. Test equating, scaling, and linking : methods and practices, 2nd edn. New York: Springer; 2004.

25. World Health Organization: International Classification of Functioning, Disability and Health (ICF). Geneva: World Health Organization; 2001.

26. Cieza A, Fayed N, Bickenbach J, Prodinger B. Refinements of the ICF Linking Rules to strengthen their potential for establishing comparability of health information. Disabil Rehabil 2016; 41: 574-583.

27. Prodinger B, Reinhardt JD, Selb M, Stucki G, Yan T, Zhang $X$ et al. Towards system-wide implementation of the International Classification of Functioning, Disability and Health (ICF) in routine practice: developing simple, intuitive descriptions of ICF categories in the ICF Generic and Rehabilitation Set. J Rehabil Med 2016; 48: 508-514.

28. Masters GN. A Rasch model for partial credit scoring. Psychometrika 1982; 47: 149-174.

29. Tennant A, Conaghan PG. The Rasch measurement model in rheumatology: what is it and why use it? When should it be applied, and what should one look for in a Rasch paper? Arthritis Rheumatol 2007; 57: 1358-1362.

30. Petrillo J, Cano SJ, McLeod LD, Coon CD. Using classical test theory, item response theory, and Rasch measurement theory to evaluate patient-reported outcome measures: a comparison of worked examples. Value in Health 2015; 18: 25-34.

31. Prodinger B, Ballert CS, Brinkhof MW, Tennant A, Post MW. Metric properties of the Spinal Cord Independence Measure - self report in a community survey. J Rehabil Med 2016; 48: 149-164.

32. Andrich D, Sheridan B, Luo G. Rasch models for measurement: RUMM2030. Perth: RUMM Laboratory Pty Ltd; 2010.

33. Rodriguez A, Reise SP, Haviland MG. Evaluating bifactor models: Calculating and interpreting statistical indices. Psychol Methods 2016; 21: 137-150.

34. Quinn HO. Bifactor models, explained common variance $(E C V)$, and the usefulness of scores from unidimensional item response theory analyses. Chapel Hill: University of North Carolina; 2014.

35. Hagell P. Testing Rating Scale unidimensionality using the principal component analysis (PCA) /t- test protocol with the Rasch model: the primacy of theory over statistics. Open J Stat 2014; 4: 456-465.

36. Wilcoxon F. Individual comparisons of grouped data by ranking methods. J Econ Entomol 1946; 39: 269.

37. Cohen J. The statistical power of abnormal-social psychological research: a review. J Abnormal Social Psychol 1962; 65: 145-153.

38. Leunbach G. A probabilistic measurement model for assessing whether two tests measure the same personal factor. Copenhagen: Danish Institute for Educational Research; 1976.

39. Kolen MJ, Brennan RL. Test equating, scaling, and linking. Methods and practices (2nd edition). New York: Springer; 2004.

40. Adroher ND, Kreiner S, Young C, Mills R, Tennant A. Test equating sleep scales: applying the Leunbach's model. BMC Med Res Methodol 2019; 19: 141.

41. Kreiner S, Nielsen T. Item analysis in DIGRAM 3.04. Part I: Guided tours. Research report 2013/06.Copenhagen: University of Copenhagen, Department of Public Health; 2013.

42. R Core Team: R. A language and environment for statistical computing. Vienna: R Foundation for Statistical Computing; 2016.

43. Bennette C, Vickers A. Against quantiles: categorization of continuous variables in epidemiologic research, and its discontents. BMC Med Res Methodol 2012; 12: 21. 
p. 8 of 15 R. Maritz et al.

Appendix 1a: Descriptive statistics, frequencies and percentages of responses to Functional Independence Measure (FIM $\left.{ }^{\mathrm{TM}}\right)$ self-care items with original and transformed coding of response options for the entire and the analysis sample

\begin{tabular}{|c|c|c|c|c|c|c|c|}
\hline \multirow{2}{*}{$\frac{\text { Domain }}{\text { Self Care }}$} & \multicolumn{2}{|c|}{ Question } & \multirow{2}{*}{$\begin{array}{l}\text { Response Option } \\
\text { Total assistance with helper }\end{array}$} & \multirow{2}{*}{$\begin{array}{l}\text { Original } \\
\text { Coding } \\
1\end{array}$} & \multirow{2}{*}{$\begin{array}{l}\text { Coding for the } \\
\text { Rasch analysis } \\
0\end{array}$} & \multirow{2}{*}{$\begin{array}{l}\begin{array}{l}\text { Complete } \\
\text { sample } \\
n(\%)\end{array} \\
90(9.1)\end{array}$} & \multirow{2}{*}{$\begin{array}{l}\begin{array}{l}\text { Analysis } \\
\text { sample } \\
n(\%)\end{array} \\
59(8.9)\end{array}$} \\
\hline & FIM A & Eating & & & & & \\
\hline & & & Maximal assistance with helper & 2 & 1 & $35(3.6)$ & $17(2.6)$ \\
\hline & & & Moderate assistance with helper & 3 & 2 & $19(1.9)$ & $10(1.5)$ \\
\hline & & & Minimal assistance with helper & 4 & 3 & $51(5.2)$ & $35(5.3)$ \\
\hline & & & Supervision or setup with helper & 5 & 4 & $160(16.2)$ & $109(16.4)$ \\
\hline & & & Modified independence with no helper & 6 & 5 & $134(13.6)$ & $87(13.1)$ \\
\hline & & & Complete independence with no helper & 7 & 6 & $496(50.4)$ & $346(52.2)$ \\
\hline & FIM B & Grooming & Total assistance with helper & 1 & 0 & $120(12.2)$ & $72(10.9)$ \\
\hline & & & Maximal assistance with helper & 2 & 1 & $57(5.8)$ & $33(5.0)$ \\
\hline & & & Moderate assistance with helper & 3 & 2 & $59(6.0)$ & $39(5.9)$ \\
\hline & & & Minimal assistance with helper & 4 & 3 & $64(6.5)$ & $50(7.5)$ \\
\hline & & & Supervision or setup with helper & 5 & 4 & $150(15.2)$ & 99 (14.9) \\
\hline & & & Modified independence with no helper & 6 & 5 & $172(17.5)$ & $117(17.6)$ \\
\hline & & & Complete independence with no helper & 7 & 6 & 363 (36.9) & $253(38.2)$ \\
\hline & FIM C & Bathing & Total assistance with helper & 1 & 0 & $251(25.5)$ & $165(24.9)$ \\
\hline & & & Moderate assistance with helper & 3 & 2 & $129(13.1)$ & $84(12.7)$ \\
\hline & & & Minimal assistance with helper & 4 & 3 & $101(10.3)$ & $71(10.7)$ \\
\hline & & & Supervision or setup with helper & 5 & 4 & $63(6.4)$ & $40(6.0)$ \\
\hline & & & Modified independence with no helper & 6 & 5 & $144(14.6)$ & $93(14.0)$ \\
\hline & & & Complete independence with no helper & 7 & 6 & $80(8.1)$ & $62(9.4)$ \\
\hline & FIM D & Dressing & Total assistance with helper & 1 & 0 & $240(24.4)$ & $159(24.0)$ \\
\hline & & Upper Body & Maximal assistance with helper & 2 & 1 & $66(6.7)$ & $46(6.9)$ \\
\hline & & & Moderate assistance with helper & 3 & 2 & $55(5.6)$ & $35(5.3)$ \\
\hline & & & Minimal assistance with helper & 4 & 3 & $103(10.5)$ & $68(10.3)$ \\
\hline & & & Supervision or setup with helper & 5 & 4 & $95(9.6)$ & $55(8.3)$ \\
\hline & & & Modified independence with no helper & 6 & 5 & $168(17.1)$ & $113(17.0)$ \\
\hline & & & Complete independence with no helper & 7 & 6 & $258(26.2)$ & $187(28.2)$ \\
\hline & FIM E & Dressing & Total assistance with helper & 1 & 0 & $543(55.1)$ & $363(54.8)$ \\
\hline & & Lower Body & Maximal assistance with helper & 2 & 1 & $84(8.5)$ & $50(7.5)$ \\
\hline & & & Moderate assistance with helper & 3 & 2 & $50(5.1)$ & $35(5.3)$ \\
\hline & & & Minimal assistance with helper & 4 & 3 & $75(7.6)$ & $42(6.3)$ \\
\hline & & & Supervision or setup with helper & 5 & 4 & $40(4.1)$ & $29(4.4)$ \\
\hline & FIM F & Toileting & Total assistance with helper & 1 & 0 & $572(58.1)$ & $374(56.4)$ \\
\hline & & & Maximal assistance with helper & 2 & 1 & $50(5.1)$ & $28(4.2)$ \\
\hline & & & Moderate assistance with helper & 3 & 2 & $16(1.6)$ & $13(2.0)$ \\
\hline & & & Minimal assistance with helper & 4 & 3 & $31(3.1)$ & $20(3.0)$ \\
\hline & & & Supervision or setup with helper & 5 & 4 & $40(4.1)$ & $26(3.9)$ \\
\hline & & & Modified independence with no helper & 6 & 5 & $122(12.4)$ & $85(12.8)$ \\
\hline & & & Complete independence with no helper & 7 & 6 & $154(15.6)$ & $117(17.6)$ \\
\hline \multirow{14}{*}{$\begin{array}{l}\text { Sphincter } \\
\text { Control }\end{array}$} & FIM G & Bladder & Total assistance with helper & 1 & 0 & $469(47.6)$ & $303(45.7)$ \\
\hline & & Management & Maximal assistance with helper & 2 & 1 & $39(4.0)$ & $25(3.8)$ \\
\hline & & & Moderate assistance with helper & 3 & 2 & $34(3.5)$ & $22(3.3)$ \\
\hline & & & Minimal assistance with helper & 4 & 3 & $30(3.0)$ & $19(2.9)$ \\
\hline & & & Supervision or setup with helper & 5 & 4 & $78(7.9)$ & $55(8.3)$ \\
\hline & & & Modified independence with no helper & 6 & 5 & $253(25.7)$ & $171(25.8)$ \\
\hline & & & Complete independence with no helper & 7 & 6 & $82(8.3)$ & $68(10.3)$ \\
\hline & FIM H & Bowel & Total assistance with helper & 1 & 0 & $508(51.6)$ & $327(49.3)$ \\
\hline & & Management & Maximal assistance with helper & 2 & 1 & $50(5.1)$ & $35(5.3)$ \\
\hline & & & Moderate assistance with helper & 3 & 2 & $27(2.7)$ & $17(2.6)$ \\
\hline & & & Minimal assistance with helper & 4 & 3 & $65(6.6)$ & $39(5.9)$ \\
\hline & & & Supervision or setup with helper & 5 & 4 & $59(6.0)$ & $42(6.3)$ \\
\hline & & & Modified independence with no helper & 6 & 5 & $194(19.7)$ & $138(20.8)$ \\
\hline & & & Complete independence with no helper & 7 & 6 & $82(8.3)$ & $65(9.8)$ \\
\hline
\end{tabular}


Appendix 1b: Descriptive statistics, frequencies and percentages of responses to Functional Independence Measure (FIM $\left.{ }^{\top M}\right)$ mobility items with original and transformed coding of response options for the entire and the analysis sample.

\begin{tabular}{|c|c|c|c|c|c|c|c|}
\hline Domain & Question & & Response Option & $\begin{array}{l}\text { Original } \\
\text { Coding }\end{array}$ & $\begin{array}{l}\text { Coding for } \\
\text { the Rasch } \\
\text { analysis }\end{array}$ & $\begin{array}{l}\text { Complete } \\
\text { sample } \\
n(\%)\end{array}$ & $\begin{array}{l}\text { Analysis } \\
\text { sample } \\
n(\%)\end{array}$ \\
\hline \multirow[t]{34}{*}{ Mobility } & \multirow[t]{6}{*}{ FIM I } & \multirow{6}{*}{$\begin{array}{l}\text { Transfers - bed/chair/ } \\
\text { wheelchair }\end{array}$} & Total assistance with helper & 1 & 0 & $368(37.4)$ & $242(36.5)$ \\
\hline & & & Moderate assistance with helper & 3 & 2 & $81(8.2)$ & $54(8.1)$ \\
\hline & & & Minimal assistance with helper & 4 & 3 & $66(6.7)$ & $48(7.2)$ \\
\hline & & & Supervision or setup with helper & 5 & 4 & $92(9.3)$ & $59(8.9)$ \\
\hline & & & Modified independence with no helper & 6 & 5 & $144(14.6)$ & $94(14.2)$ \\
\hline & & & Complete independence with no helper & 7 & 6 & $161(16.3)$ & $124(18.7)$ \\
\hline & \multirow[t]{7}{*}{ FIM J } & \multirow[t]{7}{*}{ Transfers - toilet } & Total assistance with helper & 1 & 0 & $464(47.1)$ & $297(44.8)$ \\
\hline & & & Maximal assistance with helper & 2 & 1 & $55(5.6)$ & $37(5.6)$ \\
\hline & & & Moderate assistance with helper & 3 & 2 & $59(6.0)$ & $44(6.6)$ \\
\hline & & & Minimal assistance with helper & 4 & 3 & $78(7.9)$ & $54(8.1)$ \\
\hline & & & Supervision or setup with helper & 5 & 4 & $82(8.3)$ & $51(7.7)$ \\
\hline & & & Modified independence with no helper & 6 & 5 & $134(13.6)$ & $94(14.2)$ \\
\hline & & & Complete independence with no helper & 7 & 6 & $113(11.5)$ & $86(13.0)$ \\
\hline & \multirow[t]{6}{*}{ FIM K } & \multirow[t]{6}{*}{ Transfers - bath/shower } & Total assistance with helper & 1 & 0 & $487(49.5)$ & $317(47.8)$ \\
\hline & & & Moderate assistance with helper & 3 & 2 & $57(5.8)$ & $34(5.1)$ \\
\hline & & & Minimal assistance with helper & 4 & 3 & $67(6.8)$ & $46(6.9)$ \\
\hline & & & Supervision or setup with helper & 5 & 4 & $82(8.3)$ & $55(8.3)$ \\
\hline & & & Modified independence with no helper & 6 & 5 & $130(13.2)$ & $92(13.9)$ \\
\hline & & & Complete independence with no helper & 7 & 6 & $100(10.2)$ & $76(11.5)$ \\
\hline & \multirow[t]{7}{*}{ FIM L } & \multirow[t]{7}{*}{ Walk/wheelchair } & Total assistance with helper & 1 & 0 & $199(20.2)$ & $124(18.7)$ \\
\hline & & & Maximal assistance with helper & 2 & 1 & $25(2.5)$ & $16(2.4)$ \\
\hline & & & Moderate assistance with helper & 3 & 2 & $26(2.6)$ & $13(2.0)$ \\
\hline & & & Minimal assistance with helper & 4 & 3 & $24(2.4)$ & $19(2.9)$ \\
\hline & & & Supervision or setup with helper & 5 & 4 & $92(9.3)$ & $58(8.7)$ \\
\hline & & & Modified independence with no helper & 6 & 5 & $558(56.6)$ & $387(58.4)$ \\
\hline & & & Complete independence with no helper & 7 & 6 & $61(6.2)$ & $46(6.9)$ \\
\hline & \multirow[t]{3}{*}{ FIM L(1) } & \multirow{3}{*}{$\begin{array}{l}\text { Specification: walk/ } \\
\text { wheelchair }\end{array}$} & Walk & 1 & 0 & $76(7.7)$ & $64(9.7)$ \\
\hline & & & Wheelchair & 2 & 1 & $833(84.6)$ & $547(82.5)$ \\
\hline & & & Both & 3 & 2 & $76(7.7)$ & $52(7.8)$ \\
\hline & \multirow[t]{5}{*}{ FIM M } & \multirow[t]{5}{*}{ Stairs } & Total assistance with helper & 1 & 0 & $876(88.9)$ & $575(86.7)$ \\
\hline & & & Maximal assistance with helper & 2 & 1 & $17(1.7)$ & $14(2.1)$ \\
\hline & & & Supervision or setup with helper & 5 & 4 & $23(2.3)$ & $17(2.6)$ \\
\hline & & & Modified independence with no helper & 6 & 5 & $45(4.6)$ & $37(5.6)$ \\
\hline & & & Complete independence with no helper & 7 & 6 & $11(1.1)$ & $10(1.5)$ \\
\hline
\end{tabular}


p. 10 of 15 R. Maritz et al.

Appendix 1c: Descriptive statistics, frequencies and percentages of responses to Functional Independence Measure (FIM ${ }^{\mathrm{TM}}$ ) bowel and bladder items with original and transformed coding of response options for the entire and the analysis sample

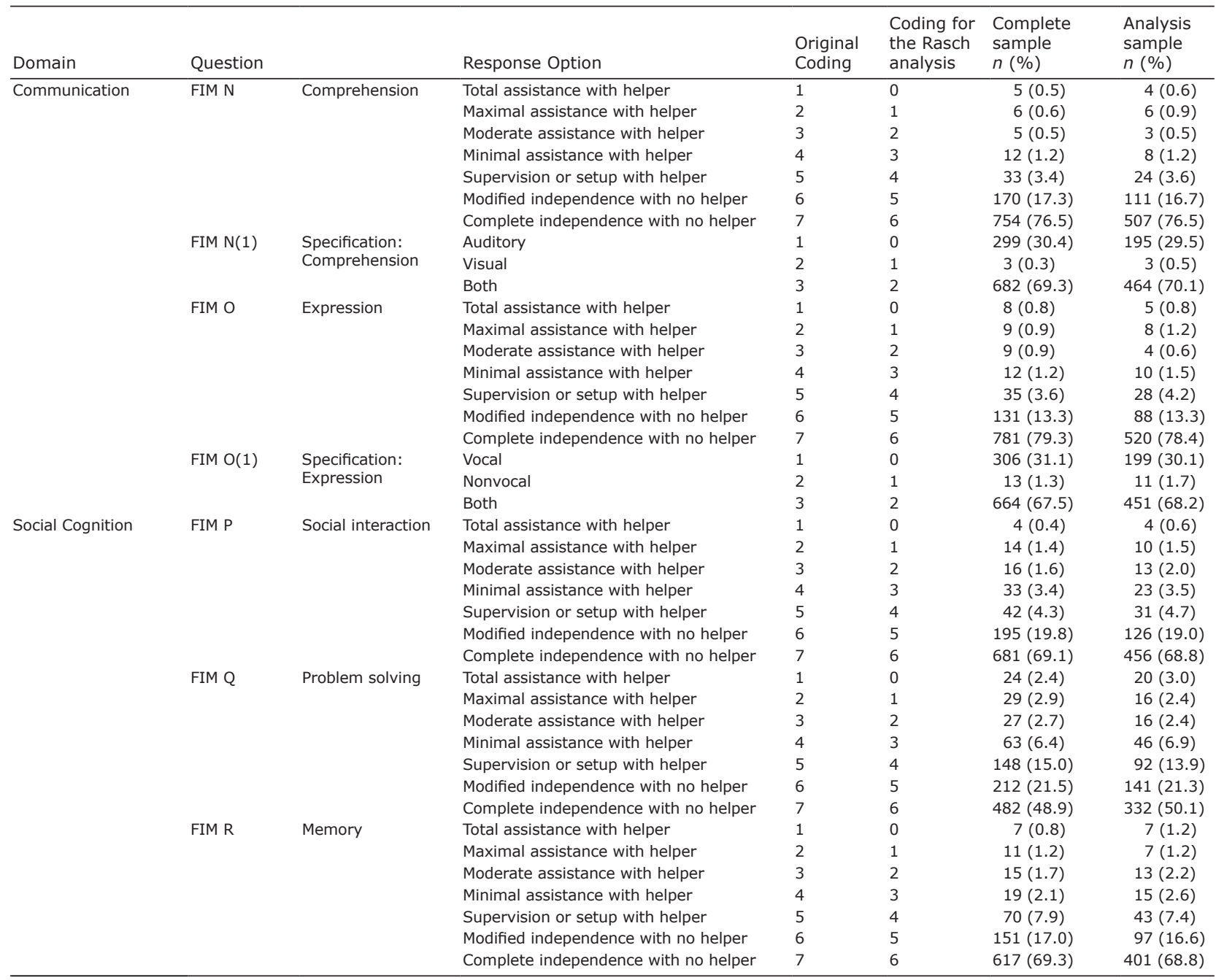


Appendix 2a: Descriptive statistics, frequencies and percentages of responses to Spinal Cord Independence Measure (SCIM) self-care items with original and transformed coding of response options for the entire and the analysis sample.

\begin{tabular}{|c|c|c|c|c|c|c|}
\hline Question & & Response Options & $\begin{array}{l}\text { Original } \\
\text { Coding }\end{array}$ & $\begin{array}{l}\text { Coding for } \\
\text { the Rasch } \\
\text { analysis }\end{array}$ & $\begin{array}{l}\text { Complete } \\
\text { sample } \\
n(\%)\end{array}$ & $\begin{array}{l}\text { Analysis } \\
\text { sample } \\
n(\%)\end{array}$ \\
\hline \multirow[t]{3}{*}{ SCIM 1} & \multirow{3}{*}{$\begin{array}{l}\text { Feeding } \\
\text { cutting, opening } \\
\text { containers, pouring, } \\
\text { bringing food to mouth, } \\
\text { holding cup } \\
\text { with fluid }\end{array}$} & Needs parenteral, gastronomy, or fully assisted oral feeding & 0 & 0 & $96(9.7)$ & $62(9.4)$ \\
\hline & & $\begin{array}{l}\text { Eats independently; needs adaptive devices or assistance only for cutting food } \\
\text { and/or pouring and/or opening containers. }\end{array}$ & 2 & 2 & $225(22.8)$ & $156(23.5)$ \\
\hline & & $\begin{array}{l}\text { Eats and drinks independently; does not require assistance or adaptive } \\
\text { devices. }\end{array}$ & 3 & 3 & $585(59.4)$ & $398(60.0)$ \\
\hline \multirow[t]{4}{*}{ SCIM 2} & \multirow{4}{*}{$\begin{array}{l}\text { Bathing - upper body } \\
\text { soaping washing, } \\
\text { drying body and head, } \\
\text { manipulating water tap }\end{array}$} & Requires total assistance & 0 & 0 & $153(15.5)$ & $98(14.8)$ \\
\hline & & Requires partial assistance & 1 & 1 & $244(24.8)$ & $172(25.9)$ \\
\hline & & $\begin{array}{l}\text { Washes independently with adaptive devices or in a specific setting (e.g. bars, } \\
\text { chair) }\end{array}$ & 2 & 2 & $304(30.9)$ & $195(29.4)$ \\
\hline & & $\begin{array}{l}\text { Washes independently; does not require adaptive devices or in a specific } \\
\text { setting (not customary for healthy people) (adss) }\end{array}$ & 3 & 3 & $284(28.8)$ & $198(29.9)$ \\
\hline \multirow[t]{3}{*}{ SCIM 3} & \multirow{3}{*}{$\begin{array}{l}\text { Bathing - lower body } \\
\text { soaping washing, } \\
\text { drying body and head, } \\
\text { manipulating water tap }\end{array}$} & Requires total assistance & 0 & 0 & $513(52.1)$ & $336(50.7)$ \\
\hline & & Requires partial assistance & 1 & 1 & $162(16.4)$ & $103(15.5)$ \\
\hline & & $\begin{array}{l}\text { Washes independently with adaptive devices or in a specific setting (e.g. bars, } \\
\text { chair) }\end{array}$ & 2 & 2 & $183(18.6)$ & $129(19.5)$ \\
\hline \multirow[t]{5}{*}{ SCIM 4} & \multirow{5}{*}{$\begin{array}{l}\text { Dressing - upper body } \\
\text { clothes, shoes, permanent } \\
\text { orthoses: dressing, } \\
\text { wearing, undressing }\end{array}$} & Requires total assistance & 0 & 0 & $218(22.1)$ & $145(21.9)$ \\
\hline & & $\begin{array}{l}\text { Requires partial assistance with clothes without buttons, zippers or laces } \\
\text { (cwobzl) }\end{array}$ & 1 & 1 & $191(19.4)$ & $126(19.0)$ \\
\hline & & $\begin{array}{l}\text { Independent with cwobzl; requires adaptive devices and/or specific settings } \\
\text { (adss) }\end{array}$ & 2 & 2 & $105(10.7)$ & $64(9.7)$ \\
\hline & & $\begin{array}{l}\text { Independent with cwobzl; does not require adss; needs assistance or adss } \\
\text { only for bzl }\end{array}$ & 3 & 3 & $125(12.7)$ & $81(12.2)$ \\
\hline & & $\begin{array}{l}\text { Dresses (any cloth) independently; does not require adaptive devices or } \\
\text { specific setting }\end{array}$ & 4 & 4 & $346(35.1)$ & $247(37.3)$ \\
\hline \multirow[t]{5}{*}{ SCIM 5} & \multirow{5}{*}{$\begin{array}{l}\text { Dressing - lower body } \\
\text { clothes, shoes, permanent } \\
\text { orthoses: dressing, } \\
\text { wearing, undressing }\end{array}$} & Requires total assistance & 0 & 0 & $551(55.9)$ & $364(54.9)$ \\
\hline & & $\begin{array}{l}\text { Requires partial assistance with clothes without buttons, zippers or laces } \\
\text { (cwobzl) }\end{array}$ & 1 & 1 & $98(9.9)$ & $62(9.4)$ \\
\hline & & $\begin{array}{l}\text { Independent with cwobzl; requires adaptive devices and/or specific settings } \\
\text { (adss) }\end{array}$ & 2 & 2 & $86(8.7)$ & $58(8.7)$ \\
\hline & & $\begin{array}{l}\text { Independent with cwobzl; does not require adss; needs assistance or adss } \\
\text { only for bzl }\end{array}$ & 3 & 3 & $107(10.9)$ & $71(10.7)$ \\
\hline & & $\begin{array}{l}\text { Dresses (any cloth) independently; does not require adaptive devices or } \\
\text { specific setting }\end{array}$ & 4 & 4 & $143(14.5)$ & $108(16.3)$ \\
\hline \multirow{2}{*}{ SCIM 6} & \multirow{2}{*}{$\begin{array}{l}\text { Grooming } \\
\text { washing hands and face, } \\
\text { brushing teeth, combing } \\
\text { hair, shaving, applying } \\
\text { makeup }\end{array}$} & Grooms independently with adaptive devices & 2 & 2 & $87(8.8)$ & $60(9.0)$ \\
\hline & & Washes independently without adaptive devices & 3 & 3 & $650(66.0)$ & $443(66.8)$ \\
\hline \multirow[t]{6}{*}{ SCIM 7} & \multirow[t]{6}{*}{ Respiration } & $\begin{array}{l}\text { Requires tracheal tube }(\mathrm{TT}) \text { and permanent or intermittent assisted ventilation } \\
\text { (IAV). }\end{array}$ & 0 & 0 & $11(1.1)$ & $10(1.5)$ \\
\hline & & $\begin{array}{l}\text { Breathes independently with } \Pi \text {; requires oxygen, much assistance in coughing } \\
\text { or } T \text { management. }\end{array}$ & 2 & 1 & $10(1.0)$ & $5(0.8)$ \\
\hline & & $\begin{array}{l}\text { Breathes independently with } \Pi \text {; requires little assistance in coughing or } \Pi T \\
\text { management. }\end{array}$ & 4 & 2 & $4(0.4)$ & $3(0.5)$ \\
\hline & & $\begin{array}{l}\text { Breathes independently without TT; requires oxygen, much assistance in } \\
\text { coughing, a mask (e.g. peep) or IAV (bipap). }\end{array}$ & 6 & 3 & $93(9.4)$ & $56(8.4)$ \\
\hline & & $\begin{array}{l}\text { Breathes independently without } T \text {; requires little assistance or stimulation for } \\
\text { coughing. }\end{array}$ & 8 & 4 & $54(5.5)$ & $33(5.0)$ \\
\hline & & Breathes independently without assistance or device. & 10 & 5 & $813(82.5)$ & $556(83.9)$ \\
\hline \multirow[t]{7}{*}{ SCIM 8} & Sphincter Management & Indwelling catheter. & 0 & 0 & $471(47.8)$ & $313(47.2)$ \\
\hline & \multirow[t]{6}{*}{ Bladder } & $\begin{array}{l}\text { Residual urine volume (RUV) }>100 \mathrm{cc} \text {; no regular catheterization or assisted } \\
\text { intermittent catheterization. }\end{array}$ & 3 & 1 & $95(9.6)$ & $59(8.9)$ \\
\hline & & $\begin{array}{l}\text { Residual urine volume (RUV) }<100 \mathrm{cc} \text { or intermittent self-catheterization; } \\
\text { needs assistance for applying drainage instrument. }\end{array}$ & 6 & 2 & $68(6.9)$ & $46(6.9)$ \\
\hline & & $\begin{array}{l}\text { Intermittent self-catheterization; uses external drainage instrument; does not } \\
\text { need assistance for applying. }\end{array}$ & 9 & 3 & $38(3.9)$ & $27(4.1)$ \\
\hline & & $\begin{array}{l}\text { Intermittent self-catheterization; continent between catheterizations; does not } \\
\text { use external drainage instrument. }\end{array}$ & 11 & 4 & $144(14.6)$ & $86(13.0)$ \\
\hline & & $\begin{array}{l}\text { RUV }<100 \mathrm{cc} \text {; needs only external urine drainage; no assistance is required for } \\
\text { drainage }\end{array}$ & 13 & 5 & $21(2.1)$ & $15(2.3)$ \\
\hline & & RUV < $100 \mathrm{cc}$; continent; does not use external drainage instrument. & 15 & 6 & $148(15.0)$ & $117(17.6)$ \\
\hline \multirow[t]{4}{*}{ SCIM 9} & Sphincter Management & $\begin{array}{l}\text { Irregular timing or very low frequency (less than once in } 3 \text { days) of bowel } \\
\text { movements }\end{array}$ & 0 & 0 & $205(20.8)$ & $139(21.0)$ \\
\hline & \multirow[t]{3}{*}{ Bowel } & $\begin{array}{l}\text { Regular timing, but requires assistance (e.g., for applying suppository); rare } \\
\text { accidents (less than twice a month). }\end{array}$ & 5 & 1 & $474(48.1)$ & $298(44.9)$ \\
\hline & & $\begin{array}{l}\text { Regular bowel movements, without assistance; rare accidents (less than twice } \\
\text { a month) }\end{array}$ & 8 & 2 & $106(10.8)$ & $69(10.4)$ \\
\hline & & Regular bowel movements, without assistance, no accidents. & 10 & 3 & $200(20.3)$ & $157(23.7)$ \\
\hline \multirow[t]{4}{*}{ SCIM 10} & \multirow{4}{*}{$\begin{array}{l}\text { Use of Toilet } \\
\text { perineal hygiene, } \\
\text { adjustment of clothes } \\
\text { before/after, use of } \\
\text { napkins or diapers }\end{array}$} & Requires total assistance. & 0 & 0 & $529(53.7)$ & $342(51.6)$ \\
\hline & & Requires partial assistance; does not clean self & 1 & 1 & $90(9.1)$ & $63(9.5)$ \\
\hline & & Requires partial assistance; cleans self independently & 2 & 2 & $58(5.9)$ & $35(5.3)$ \\
\hline & & $\begin{array}{l}\text { Uses toilet independently in all tasks but needs adaptive devices or special } \\
\text { setting (e.g. bars) }\end{array}$ & 4 & 3 & $156(15.8)$ & 109 (16.4) \\
\hline
\end{tabular}


p. 12 of 15 R. Maritz et al.

Appendix 2b: Descriptive statistics, frequencies and percentages of responses to Spinal Cord Independence Measure (SCIM) bowel and bladder management items (including respiration) with original and transformed coding of response options for the entire and the analysis sample

\begin{tabular}{|c|c|c|c|c|c|c|c|}
\hline Domain & Question & & Response Options & $\begin{array}{l}\text { Original } \\
\text { Coding }\end{array}$ & $\begin{array}{l}\text { Coding for } \\
\text { the Rasch } \\
\text { analysis }\end{array}$ & $\begin{array}{l}\text { Complete } \\
\text { sample } \\
n(\%)\end{array}$ & $\begin{array}{l}\text { Analysis } \\
\text { sample } \\
n(\%)\end{array}$ \\
\hline \multirow[t]{10}{*}{ Mobility } & \multirow[t]{4}{*}{ SCIM 11} & \multirow[t]{4}{*}{ Mobility (room and toilet) } & $\begin{array}{l}\text { Needs assistance in all activities: turning upper body } \\
\text { in bed, turning lower body in bed, sitting } \\
\text { up in bed, doing push-ups in wheelchair, with or } \\
\text { without adaptive devices, nut not with } \\
\text { electronic aids. }\end{array}$ & 0 & 0 & $326(33.1)$ & $216(32.6)$ \\
\hline & & & Performs one of the activities without assistance. & 2 & 1 & $189(19.2)$ & $124(18.7)$ \\
\hline & & & $\begin{array}{l}\text { Performs two or three of the activities without } \\
\text { assistance. }\end{array}$ & 4 & 2 & $169(17.2)$ & $104(15.7)$ \\
\hline & & & $\begin{array}{l}\text { Performs all the bed mobility and pressure release } \\
\text { activities independently. }\end{array}$ & 6 & 3 & $301(30.6)$ & $219(33.0)$ \\
\hline & \multirow[t]{3}{*}{ SCIM 12} & Transfers: bed - wheelchair & Requires total assistance & 0 & 0 & $382(38.8)$ & $260(39.2)$ \\
\hline & & $\begin{array}{l}\text { locking wheelchair, lifting } \\
\text { footrests, removing and }\end{array}$ & $\begin{array}{l}\text { Needs partial assistance and/or supervision, and/or } \\
\text { adaptive devices (e.g. sliding board) }\end{array}$ & 1 & 1 & $323(32.8)$ & $210(31.7)$ \\
\hline & & $\begin{array}{l}\text { adjusting arm rests, } \\
\text { transferring, lifting feet }\end{array}$ & Independent (or does not require wheelchair) & 2 & 2 & $280(28.4)$ & $193(29.1)$ \\
\hline & \multirow[t]{3}{*}{ SCIM 13} & $\begin{array}{l}\text { Transfers: wheelchair- toilet- } \\
\text { tub }\end{array}$ & Requires total assistance & 0 & 0 & $495(50.3)$ & $331(49.9)$ \\
\hline & & $\begin{array}{l}\text { if uses toilet wheelchair: } \\
\text { transfers to and from; if uses }\end{array}$ & $\begin{array}{l}\text { Needs partial assistance and/or supervision, and/or } \\
\text { adaptive devices (e.g. sliding board) }\end{array}$ & 1 & 1 & $392(39.8)$ & $259(39.1)$ \\
\hline & & regular wheelchair: locking & Independent (or does not require wheelchair) & 2 & 2 & $98(9.9)$ & $73(11.0)$ \\
\hline
\end{tabular}
wheelchair, lifting footrests, removing and adjusting armrests, transferring, lifting feet

SCIM 14 Mobility Indoors

Requires total assistance

Needs electric wheelchair or partial assistance to operate manual wheelchair

Moves independently in manual wheelchair

Requires supervision while walking (with or without devices)

Walks with a walking frame or crutches (swing)

Walks with a crutches or two canes (reciprocal walking)

Walks with one cane

Needs leg orthosis only

Walks without walking aids

SCIM 15 Mobility for Moderate Distances Requires total assistance (10-100 meters)

Needs electric wheelchair or partial assistance to operate manual wheelchair

Moves independently in manual wheelchair

Requires supervision while walking (with or without devices)

Walks with a walking frame or crutches (swing)

Walks with a crutches or two canes (reciprocal walking)

Walks with one cane

Needs leg orthosis only

Walks without walking aids

SCIM 16 Mobility Outdoors

Requires total assistance

(more than 100 meters)

Needs electric wheelchair or partial assistance to operate manual wheelchair

Moves independently in manual wheelchair

$11(21.4) \quad 150(22.6)$

205 (20.8) $127(19.2)$

$398(40.4) \quad 256(38.6)$

$32(3.2) \quad 20(3.0)$

$39(4.0) \quad 29(4.4)$

$31(3.1) \quad 20(3.0)$

$6(0.6) \quad 6(0.9)$

$7(0.7) \quad 6(0.9)$

$56(5.7) \quad 49(7.4)$

$223(22.6) \quad 160(24.1)$

$224(22.7) \quad 143(21.6)$

$374(38.0) \quad 234(35.3)$

$35(3.6) \quad 23(3.5)$

$33(3.4) \quad 25(3.8)$

$40(4.1) \quad 27(4.1)$

$7(0.7) \quad 7(1.1)$

$4(0.4) \quad 3(0.5)$

$45(4.6) \quad 41(6.2)$

$296(30.1) \quad 211(31.8)$

$394(40.0) \quad 245(37.0)$

devices)

$\begin{array}{lllll}\text { Walks with a walking frame or crutches (swing) } & 4 & 4 & 27(2.7) & 21(3.2)\end{array}$

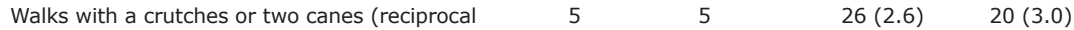

walking)

Walks with one cane

Needs leg orthosis only

Walks without walking aids

$4(0.4) \quad 4(0.6)$

$4(0.4) \quad 3(0.5)$

$34(3.5) \quad 30(4.5)$

$\begin{array}{lllrl}\text { Unable to ascend or descend stairs } & 0 & 0 & 805(81.7) & 531(80.1) \\ \text { Ascends and descends at least 3 steps with support or } 1 & 1 & 56(5.7) & 38(5.7)\end{array}$

supervision of ar

Ascends and descends at least 3 steps with support of $2 \quad 87(8.8) \quad 63(9.5)$

handrail and/or crutch or cane

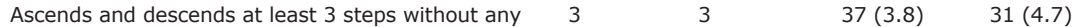

SCIM 18 Transfers: Wheelchair-car support or supervision

Requires total assistance

Needs partial assistance and/or supervision and/or approaching car, locking

adaptive device

foetrest, removing an- and

from car, bringing wheelchair

Transfers independent; does not require adaptive

devices (or does not require wheelchair)

SCIM 19 Transfers: ground - wheelchair Requires assistance

Transfers independent with or without adaptive devices (or does not require wheelchair)

$568(57.7) \quad 386(58.2)$

$306(31.1) \quad 194(29.3)$

$111(11.3) \quad 83(12.5)$

$851(86.4) \quad 563(84.9)$

$134(13.6) \quad 100(15.1)$ 
Appendix 2c: Descriptive statistics, frequencies and percentages of responses to Spinal Cord Independence Measure (SCIM) mobility items with original and transformed coding of response options for the entire and the analysis sample

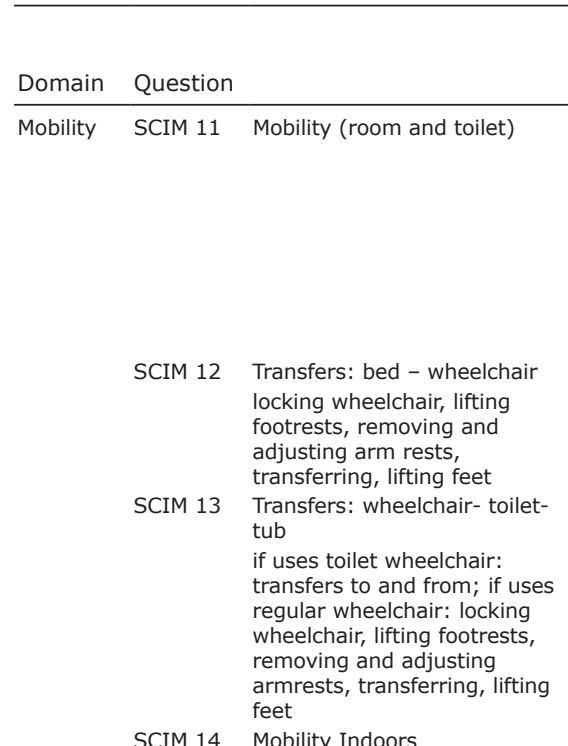

Requires total assistance

Needs electric wheelchair or partial assistance to operate manual wheelchair

Moves independently in manual wheelchair

Requires supervision while walking (with or without devices)

Walks with a walking frame or crutches (swing) 4

Walks with a crutches or two canes (reciprocal walking) 5

Walks with one cane

Needs leg orthosis only

Walks without walking aids

SCIM 15 Mobility for Moderate Distances (10-100 mtrs)

Requires total assistance

Needs electric wheelchair or partial assistance to operate manual wheelchair

Moves independently in manual wheelchair

Requires supervision while walking (with or without devices)

Walks with a walking frame or crutches (swing) 4

Walks with a crutches or two canes (reciprocal walking) 5

Walks with one cane

Needs leg orthosis only

Walks without walking aids

SCIM 16 Mobility Outdoors (more than Requires total assistance 100 meters)

Needs electric wheelchair or partial assistance to operate manual wheelchair

Moves independently in manual wheelchair

Requires supervision while walking (with or without devices)

Walks with a walking frame or crutches (swing)

Walks with a crutches or two canes (reciprocal walking) 5

Walks with one cane

Needs leg orthosis only

Walks without walking aids

Unable to ascend or descend stairs

Ascends and descends at least 3 steps with support or 1 supervision of another person

Ascends and descends at least 3 steps with support of 2 handrail and/or crutch or cane

Ascends and descends at least 3 steps without any

support or supervision

Requires total assistance

Needs partial assistance and/or supervision and/or adaptive devices

Transfers independent; does not require adaptive 2 devices (or does not require wheelchair) wheelchair, removing armand footrests, transferring to and from car, bringing wheelchair into and out of car

SCIM 19 Transfers: ground wheelchair
Coding for Complete Analysis

riginal the Rasch sample sample

Coding analysis $n(\%) \quad n(\%)$

2

42

$169(17.2) \quad 104(15.7)$

$301(30.6) \quad 219(33.0)$

382 (38.8) $260(39.2)$

$323(32.8) \quad 210(31.7)$

280 (28.4) $193(29.1)$

$495(50.3) \quad 331(49.9)$

$392(39.8) \quad 259$ (39.1)

$98(9.9) \quad 73(11.0)$

$2 \quad 2$

211 (21.4) $150(22.6)$

205 (20.8) $127(19.2)$

398 (40.4) $256(38.6)$

$32(3.2) \quad 20(3.0)$

$39(4.0) \quad 29(4.4)$

$31(3.1) \quad 20(3.0)$

$6(0.6) \quad 6(0.9)$

$7(0.7) \quad 6(0.9)$

$56(5.7) \quad 49(7.4)$

$223(22.6) \quad 160(24.1)$

224 (22.7) $143(21.6)$

374 (38.0) $234(35.3)$

$35(3.6) \quad 23(3.5)$

33 (3.4) $25(3.8)$

$40(4.1) \quad 27(4.1)$

$7(0.7) \quad 7(1.1)$

$4(0.4) \quad 3(0.5)$

$45(4.6) \quad 41(6.2)$

296 (30.1) $211(31.8)$

$394(40.0) \quad 245(37.0)$

183 (18.6) $117(17.6)$

$17(1.7) \quad 12(1.8)$

$27(2.7) \quad 21(3.2)$

$26(2.6) \quad 20(3.0)$

$4(0.4) \quad 4(0.6)$

$4(0.4) \quad 3(0.5)$

$34(3.5) \quad 30(4.5)$

$805(81.7) \quad 531(80.1)$

$56(5.7) \quad 38(5.7)$

$87(8.8) \quad 63(9.5)$

$37(3.8) \quad 31(4.7)$

568 (57.7) $386(58.2)$

$306(31.1) \quad 194(29.3)$

$111(11.3) \quad 83(12.5)$

$851(86.4) \quad 563(84.9)$

$134(13.6) \quad 100(15.1)$ 
p. 14 of 15 R. Maritz et al.

Appendix 3: Person-Item map for the co-calibration of FIM $^{\mathrm{TM}}$ motor \& SCIM

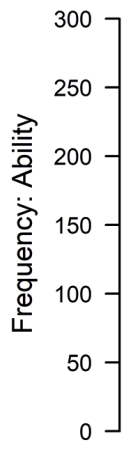

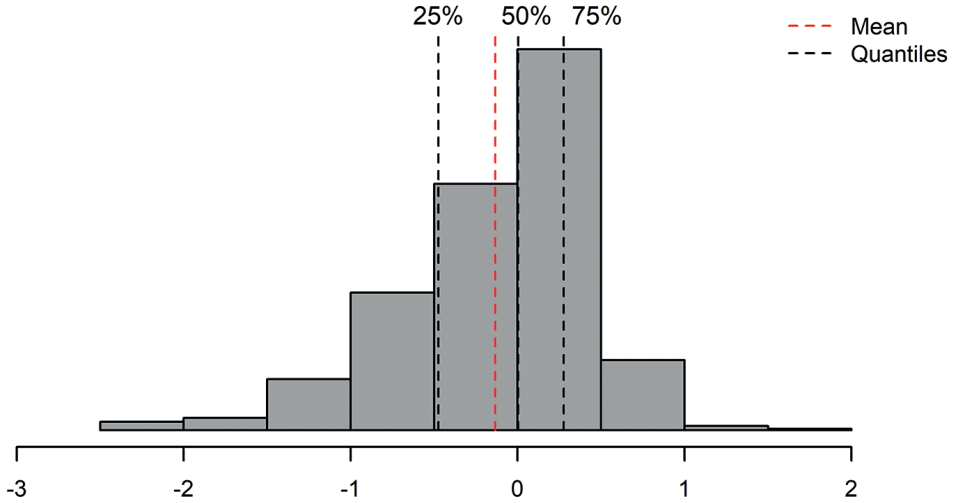

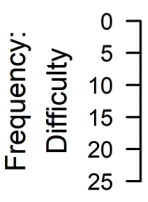

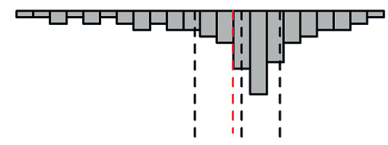

$25 \% 50 \% 75 \%$

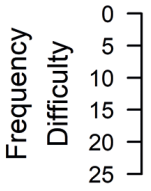

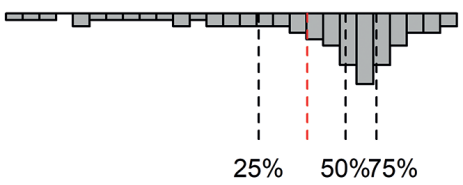

FIM $^{T M}$

SCIM 
Appendix 4: Spinal Cord Independence Measure (SCIM) total scores and corresponding Rasch transformed Functional Independence Measure $\left(\mathrm{FIM}^{\mathrm{TM}}\right)$ motor scores

\begin{tabular}{ccll}
\hline SCIM score (0 to 37) & Rasch based FIM ${ }^{T M}$ motor score & SCIM score (38-75) & Rasch based FIM ${ }^{T M}$ motor score \\
\hline 0 & 0 & 38 & 54 \\
1 & 0 & 39 & 55 \\
2 & 0 & 40 & 56 \\
3 & 1 & 41 & 57 \\
4 & 1 & 42 & 58 \\
5 & 2 & 43 & 59 \\
6 & 2 & 44 & 60 \\
7 & 3 & 45 & 60 \\
8 & 4 & 46 & 61 \\
9 & 5 & 47 & 62 \\
10 & 6 & 48 & 62 \\
11 & 7 & 49 & 63 \\
12 & 9 & 50 & 63 \\
13 & 10 & 51 & 64 \\
14 & 11 & 52 & 64 \\
15 & 13 & 53 & 65 \\
16 & 14 & 54 & 65 \\
17 & 15 & 55 & 66 \\
18 & 17 & 56 & 66 \\
19 & 18 & 57 & 67 \\
20 & 19 & 58 & 67 \\
21 & 21 & 59 & 68 \\
22 & 23 & 60 & 68 \\
23 & 24 & 61 & 69 \\
24 & 26 & 62 & 69 \\
25 & 28 & 63 & 70 \\
26 & 30 & 64 & 70 \\
27 & 32 & 65 & 71 \\
28 & 35 & 66 & 71 \\
29 & 37 & 67 & 72 \\
30 & 39 & 68 & 73 \\
31 & 42 & 69 & 74 \\
32 & 44 & 70 & 75 \\
33 & 46 & 71 & 75 \\
34 & 48 & 72 & 76 \\
35 & 50 & 73 & 78 \\
36 & 51 & 75 & \\
37 & 53 & & 73 \\
\end{tabular}

